\title{
Regulação Emocional no Trabalho: um Estudo de Caso após Desastre Aéreo
}

Emotional Regulation at Work: A Case Study after Air Disaster

Regulación Emocional en el Trabajo: un Estudio de Caso post Desastre Aéreo

Sonia Maria

Guedes Gondim

Universidade Federal da

Bahia

Jairo Eduardo

Borges-Andrade

Universidade de Brasília

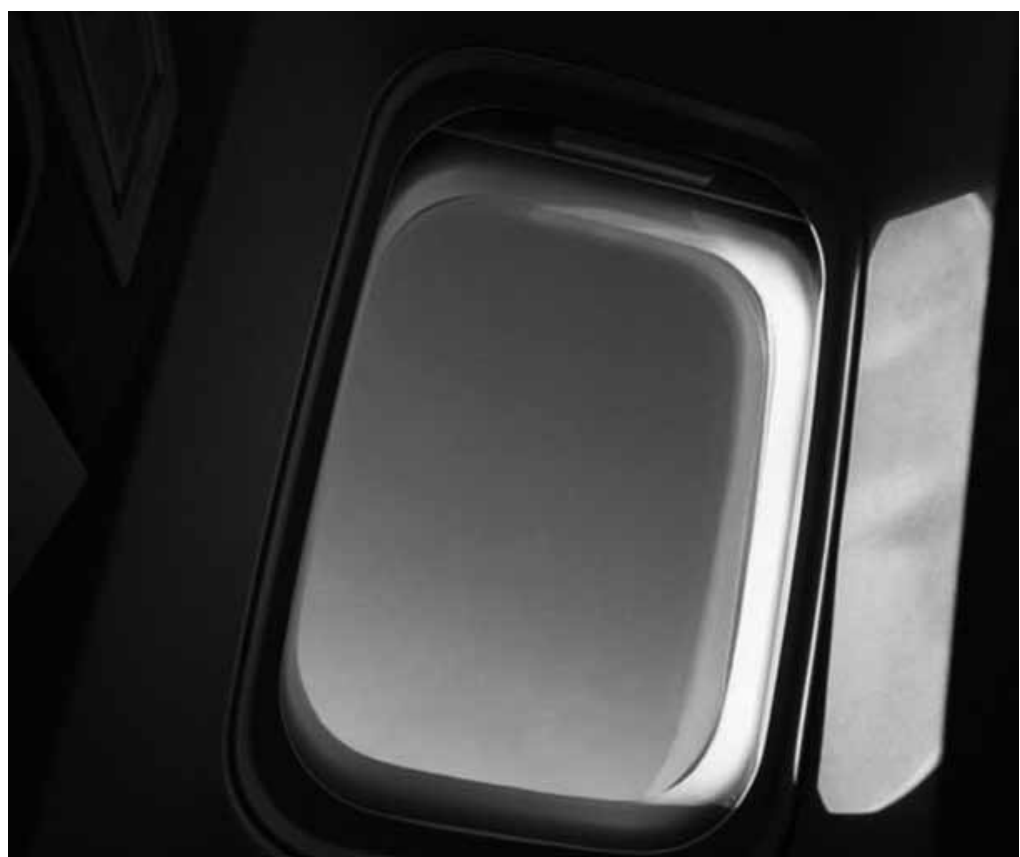


Resumo: Um dos objetivos deste estudo foi analisar as estratégias de regulação emocional dos profissionais de uma empresa aérea brasileira após acidente fatal ocorrido em 2006. Participaram do estudo qualitativo 47 aeroviários: agentes de aeroportos, profissionais de recursos humanos, comandantes, comissários e copilotos. Os dados foram coletados em janeiro de 2007, em entrevistas grupais guiadas por um roteiro semiestruturado. A duração de cada uma delas variou de 1 a 2 horas, e foram realizadas em uma sala no próprio aeroporto ou na sede da empresa. Após esclarecimentos sobre os objetivos da pesquisa e consentimento livre dos participantes, as entrevistas foram gravadas para posterior identificação das demandas de trabalho surgidas após o acidente e das estratégias de regulação emocional usadas. As estratégias de ação profunda (seleção de situação e reavaliação cognitiva) se apresentaram centrais nos discursos dos aeroviários, mais do que as estratégias superficiais (supressão de emoções ou manifestações fisiológicas). Os resultados ainda revelaram que a certeza de que a empresa não tinha culpa no acidente contribuiu positivamente. Mesmo diante de muitas e diversificadas demandas de trabalho emocional, os aeroviários relataram menos impactos negativos em seu bem-estar e mais lealdade organizacional e investimento nas mudanças de seus estados internos emocionais.

Palavras-chave: Psicologia do trabalho. Trabalho emocional. Regulação emocional. Desastre Aéreo.

\begin{abstract}
One of the main objectives of this study was to analyze the emotional regulation strategies used by employees of a Brazilian air company after a fatal accident in 2006. It is a qualitative study with the participation of 47 workers, including airport and flight attendants, human resource professionals, pilots and co-pilots. Data collection occurred in January 2007, through group interviews that were coordinated by one of the authors and guided by semi-structured forms. Each interview lasted 1 to 2 hours. These interviews were developed in an airport room or in the company headquarters. Following an explanation of the research objectives and the free consent of the participants, they were recorded for later identification of the working demands which happened after the fatal disaster, as well as the emotional regulation strategies which emerged. Deep action strategies (selection of situation and cognitive reassessment) were the central aspects of the workers' reports, when compared to superficial action strategies (suppression of emotions and physiological reactions). The findings also suggest that the strong belief that the company could not be held responsible for the disaster had a positive effect. The workers, even under several and diversified demands for emotional work, reported less negative impacts on their well-being, more organizational loyalty and more investments on changing their internal emotional states.
\end{abstract}

Keywords: Work psychology. Emotional labor. Emotional regulation. Air Disaster.

Resumen: Uno de los objetivos de este estudio fue analizar las estrategias de regulación emocional de los profesionales de una empresa aérea brasileña post accidente fatal ocurrido en 2006. Participaron del estudio cualitativo 47 trabajadores del sector aéreo: Palabras-llave: Psicología del trabajo. Trabajo emocional. Regulación emocional agentes de aeropuertos, profesionales de recursos humanos, comandantes, comisarios y copilotos. Los datos fueron colectados en enero de 2007, en entrevistas de grupo guiadas por un guión semi-estructurado. La duración de cada una de ellas varió de 1 a 2 horas, y fueron realizadas en una sala en el propio aeropuerto o en la sede de la empresa. Después de aclaraciones sobre los objetivos de la pesquisa y consentimiento libre de los participantes, las entrevistas fueron grabadas para posterior identificación de las demandas de trabajo surgidas después del accidente y de las estrategias de regulación emocional usadas. Las estrategias de acción profunda (selección de situación y reevaluación cognoscitiva) se presentaron centrales en los discursos de los trabajadores del sector aéreo, más que las estrategias superficiales (supresión de emociones o manifestaciones fisiológicas). Los resultados aún revelaron que la certeza de que la empresa no tenía culpa en el accidente aportó positivamente. Aún así delante de muchas y diversificadas demandas de trabajo emocional, los trabajadores del sector aéreo relataron menos impactos negativos en su bienestar y más lealtad organizacional e inversión en los cambios de sus estados internos emocionales.

Palabras clave: Psicología del trabajo. Trabajo emocional. Regulación emocional. Desastre Aéreo.

\begin{abstract}
As emoções estão presentes em toda a história da vida humana. Isso é flagrantemente reconhecido, mas não é fácil defini-las, pois elas constituem manifestação holística complexa e resultante da integração de múltiplos componentes, em que estão
\end{abstract}

envolvidos aspectos fisiológicos, expressões faciais, consciência e experiência subjetiva. Muitas tentativas foram feitas para distinguilas de conceitos correlatos, como os afetos, sentimentos, humores e temperamento, e de outros processos mentais, como a cognição. 
Mas não existe pleno acordo sobre sua definição.

A emoção ora é caracterizada como uma resposta fisiológica automática em reação a estímulos internos e externos (Ekman, Friesen, \& Ellsworth, 1972; Izard, 1977; James, 1884; Tomkins, 1962), ora como um estado mental emergente desencadeado pela avaliação cognitiva de um evento, e objetiva orientar as ações momentâneas (Arnold \& Gasson, 1954; Fridja, 1986; Lazarus, 1966). Há os que valorizam os componentes cognitivos e avaliativos das emoções, afirmando que um mesmo evento pode gerar reações distintas nos indivíduos (Scherer, 1999), e os que dão atenção ao fato de serem manifestações construídas nas interações sociais e influenciadas pela cultura (Averill, 1980; Harré, 1986; Lewis \& Michalson, 1983; Lutz, 1988; Mesquita, 2003; Parkinson, Fischer, \& Manstead, 2005; Saarni, 2004; Turner \& Stets, 2005). Embora todas essas perspectivas teóricas isoladas sejam importantes na consideração do fenômeno da emoção, a tendência mais atual é reconhecer que emoções são processos biopsicoculturais e, para sua completa apreensão, é preciso adotar múltiplas abordagens (Gondim \& Alvaro, n.d.; Röttger-Rössler \& Markowitsch, 2009).

As abordagens culturalista e do construcionismo social trazem contribuições relevantes para a discussão da regulação emocional, objeto de interesse deste artigo. Elas afirmam que as emoções não podem ser compreendidas apenas como experiências subjetivas individuais, mas como um fenômeno emergente na vida social. Grande parte do repertório emocional dos indivíduos seria conseqüência da avaliação pessoal da violação de normas sociais e morais aprendidas ao longo do processo de socialização (Elster, 2007).

O ser humano seria dotado de dois grandes repertórios de emoções: 1) básicas, fruto da herança filogenética que, uma vez ativadas, oferecem prontidão de resposta a situações de atração e repulsão, fuga e luta; 2) secundárias, aprendidas ao longo do processo de socialização (Damasio, 1994), com papel fundamental na construção e na regulação das interações sociais. As primeiras, apesar de seu caráter filogenético, também seriam reguladas pelo contexto social e cultural que definiria como, quando, quanto e onde expressá-las. Desse modo, a livre expressão de emoções negativas, por exemplo, poderia ser estimulada e considerada sinal de autenticidade pessoal em algumas culturas, ao passo que, em outras, ela seria desestimulada pelos riscos de desencadear reações adversas em outros indivíduos e levar ao rompimento dos laços sociais.

Por que as pessoas precisam regular suas emoções? Conformar-se às expectativas sociais, evitar sofrimento pessoal, manter a saúde física e psíquica são algumas razões. Essa regulação ainda assegura a qualidade dos relacionamentos familiares, amorosos, de amizade e no trabalho, pois a expressão de emoções negativas às vezes gera conflito e desprazer na outra pessoa, do mesmo modo que a manifestação de emoções positivas pode tornar as relações mais acolhedoras e prazerosas (Niedenthal, Krauth-Gruber, \& Ric, 2006). Regular as próprias emoções para se ajustar às normas sociais e levar em conta os sentimentos das outras pessoas são duas características muito valorizadas no mundo contemporâneo.

A regulação emocional é definida como processos conscientes, inconscientes, automáticos e controlados de mudança da expressão emocional e dos estados internos para modificar a experiência pessoal (Gross, 1998, 1999). Faz parte, ao lado das estratégias de coping, dos mecanismos de defesa do ego e dos processos de regulação do humor, 
O trabalho

emocional por demanda da organização consiste na exibição de emoções não autênticas para cumprir normas e regras organizacionais, e por demanda da ocupação consiste na expressão de emoções compatíveis com a natureza e com as exigências da ocupação (frontstage, na terminologia de Boyle, 2005). de um processo ainda mais amplo, que é o da regulação afetiva. Esse autor distingue dois grandes grupos de estratégias de regulação emocional, focadas nos aspectos antecedentes e nos conseqüentes.

Nas primeiras, focadas nos aspectos antecedentes, o indivíduo controla a situação e a percepção da situação desencadeadora de emoções por meio da seleção ou da modificação da situação, atenção posicionada e mudança cognitiva. A seleção da situação consiste em aproximar ou se distanciar de pessoas, objetos e eventos para evitar emoções indesejáveis ou fazer vir à tona emoções desejáveis; a modificação da situação consiste em expressar emoções intencionais para mudar o curso da interação em andamento; a atenção posicionada consiste em redirecionar o foco da atenção para: i) distração, que foca aspectos não emocionais da situação ou em outros eventos mais prazerosos; ii) concentração, que foca uma outra atividade para evitar pensar na situação que evoca a emoção, e iii) ruminação, que foca demasiadamente o evento eliciador da emoção e suas conseqüências, com o objetivo de esgotar as possibilidades de se sofrer pelo evento, fazendo-o perder a sua força. A mudança cognitiva consiste em negar e interpretar positiva ou negativamente, comparar o que se sente com o que outras pessoas sentem em situações semelhantes ou reavaliar a situação de uma perspectiva distinta para atenuar o seu impacto emocional.

$\mathrm{Na}$ regulação focada nos aspectos conseqüentes, o indivíduo tenta mudar os estados fisiológicos pessoais e a expressão da emoção, uma vez que ela tenha sido eliciada. As estratégias para lidar com os aspectos fisiológicos se referem às ações para atenuar ou compensar os impactos emocionais por meio de exercícios respiratórios, de biofeedback e de relaxamento, e ainda pelo uso de tranqüilizantes, relaxantes musculares, álcool, comida e cigarro. A regulação da expressão também pertence a esse grupo de estratégias focadas nos aspectos conseqüentes, e é feita por meio da supressão (tentar não mostrar) ou da intensificação (fazer questão de mostrar) para modular a experiência emocional. Há ainda uma outra estratégia de regulação focada nos aspectos conseqüentes, que é o compartilhamento social das emoções. Após experiências de forte impacto emocional negativo, as pessoas escrevem em diários e também conversam com amigos ou até mesmo desconhecidos sobre os seus sentimentos na tentativa de atenuá-los ou modificá-los (Rimé, Mesquita, Philippot, \& Boca, 1991), conseguir suporte e efetuar comparações que permitam a reavaliação de sentimentos (Rime, Finkenauer, Luminet, Zech, \& Philippot, 1998).

A regulação emocional é um processo fundamental na vida social, e está presente em todas as esferas de inserção humana. Isso inclui o mundo do trabalho; no entanto, as emoções e suas relações com o trabalho não podem ser entendidas apenas na perspectiva dos processos de regulação emocional. Miller, Considine e Gardner (2007), por exemplo, identificam cinco perspectivas da abordagem das emoções no trabalho: trabalho emocional por demanda da organização, trabalho emocional por demanda da ocupação, emoções com o trabalho, emoções no trabalho e, por fim, emoções em relação ao trabalho. O trabalho emocional por demanda da organização consiste na exibição de emoções não autênticas para cumprir normas e regras organizacionais, e por demanda da ocupação consiste na expressão de emoções compatíveis com a natureza e com as exigências da ocupação (frontstage, na terminologia de Boyle, 2005). Emoções com o trabalho se referem às que emergem nas relações com colegas de trabalho (backstage, na terminologia de Boyle), e as emoções no 
trabalho dizem respeito às que surgem fora do ambiente de trabalho, embora repercutam nele (offstage, na terminologia de Boyle, 2005). As emoções em relação ao trabalho se referem ao trabalho como alvo da emoção, dentre as quais se destaca a satisfação com o trabalho, estudada desde as primeiras décadas do século passado.

O fenômeno de gerenciar estados emocionais pessoais para expressar o que é compatível com as regras organizacionais e ocupacionais e, portanto, para garantir o êxito no desempenho de atividades remuneradas ou para a manutenção do emprego, como moeda de troca e fidelização do cliente, é denominado trabalho emocional. Esse nome foi dado por Hochschild (1979, 1983), que, embasada na perspectiva dramatúrgica de Goffman (1959), se refere a dois tipos de estratégias de gerenciamento da emoção usadas por um ator: as de superfície e as profundas. As primeiras atuam na mudança da expressão, sem modificar os sentimentos internos, e as segundas constituem um esforço consciente de mudança desses sentimentos para conseguir exibir a emoção requerida. No entendimento da autora, o trabalho emocional seria o esforço dos trabalhadores em expressar emoções e sentimentos não espontâneos com o intuito de realizar as metas organizacionais, o que traria prejuízos ao seu bem-estar subjetivo (Grove \& Fisk, 1989).

O trabalho emocional assume um outro sentido na perspectiva de Ashforth e Humphrey (1993), apesar de ser definido de modo semelhante ao anterior, como o ato de exibir emoções apropriadas para atender às demandas ocupacionais e organizacionais. Enquanto a ênfase daquela autora é no gerenciamento de emoções (esforço para exibir uma emoção), a desses autores é na análise dos fatores externos que tornam a expressão das emoções automática e rotineira. Em vez de tratarem o trabalho emocional apenas como algo que pode prejudicar o bem-estar subjetivo, vêem-no como positivamente relacionado ao bom desempenho individual e organizacional e até mesmo contributivo para a efetividade na realização de tarefas.

O trabalho emocional foi ainda definido, por Morris e Feldman (1996), como o esforço, o planejamento e o controle necessários para expressar a emoção desejada durante a interação interpessoal. A ênfase desses autores é em como as emoções são expressas e parcialmente construídas nas interações sociais. O trabalho emocional, destarte, seria caracterizado a partir do arranjo de demandas externas e da habilidade individual em lidar com essas demandas. A freqüência das interações, a intensidade e a duração da interação, a variedade das emoções requeridas e também a dissonância emocional dariam a configuração final do trabalho emocional. A novidade dessa abordagem está na inclusão da dissonância, ou na percepção de incongruência entre a emoção sentida e a expressada, como um importante filtro das demandas sociais e organizacionais. As pressões organizacionais e ocupacionais com vistas a um desempenho emocional seriam mediadas tanto por fatores contingenciais relativos às rotinas de trabalho quanto pela tolerância individual à dissonância.

Dentre as três estratégias de regulação antecedentes, seleção da situação, atenção posicionada e reavaliação da situação, Grandey (2000) afirma que as duas últimas são consideradas as mais importantes no trabalho emocional no setor de serviços, visto que o trabalhador freqüentemente não tem como evitar as situações de interação com o cliente nesse setor. A atenção posicionada é muito usada quando a atenção é focada em eventos que podem ajudar a trazer emoções positivas e bom humor para uma situação 
pouco prazerosa (articulação entre distração e concentração). A reavaliação cognitiva é considerada por esse autor a mais efetiva para atenuar o impacto emocional negativo nas interações com clientes e consumidores. Hochschild (1979, 1983) exemplifica o seu uso ao mencionar que as comissárias de bordo são treinadas para pensar que os passageiros agem como crianças, para que não sintam raiva deles. Lazarus (1966) também afirma que essa estratégia é eficaz ao interpretar situações conflituosas como desafios, em vez de fontes de estresse.

Do mesmo modo que não há respostas conclusivas sobre os malefícios e benefícios na regulação de emoções, não há consenso sobre os impactos do processo de regulação emocional decorrentes do trabalho emocional. Rafaeli e Sutton (1987), por um lado, afirmam que engajar-se em uma ação profunda para tentar mudar o sentimento interno, exibindo-o de modo autêntico, é um forte indício de que o trabalhador está envolvido emocionalmente com a organização e com sua ocupação, a ponto de fazer algo por ela. Por outro lado, Hochschild (1983) alerta que o uso freqüente de estratégias de ação superficial provoca grande prejuízo ao bemestar do trabalhador, pelo enorme desgaste de fingir o que não se sente.

O principal objetivo do estudo aqui apresentado foi analisar as estratégias de regulação emocional dos profissionais da $\mathrm{Gol}$ Linhas Aéreas Inteligentes após o acidente fatal ocorrido no dia 29 de setembro de 2006. Uma das razões para desenvolvê-lo foi o fato de ter sido o primeiro e mais grave acidente dessa empresa, que estava no mercado há aproximadamente sete anos e que construiu sua imagem institucional alicerçada na gestão inovadora, na frota moderna e nos excelentes padrões de segurança. A queda do avião, que matou todas as 154 pessoas a bordo entre tripulantes e passageiros, ocorreu após colisão no ar com outra aeronave de pequeno porte. Deixou comovida a opinião pública que acompanhou de perto o sofrimento e a dor de familiares, amigos e colegas de trabalho das vítimas. Com base na tipologia de Gross (1998) e no modelo simplificado de Grandey (2000) de trabalho emocional e estratégias de regulação emocional, foi construído um modelo teórico de análise (Figura 1) para a presente investigação, que será detalhado mais adiante.

\section{Método}

O estudo, de natureza qualitativa, contou com a participação de 47 aeroviários, dentre os quais 16 agentes de aeroporto, 28 tripulantes, incluindo comandantes, copilotos e comissários, e 3 profissionais do setor de recursos humanos (RH). Embora a empresa tenha autorizado a coleta de dados em seu espaço e a divulgação de seu nome em publicações sobre os resultados da pesquisa e indicado quem seriam os participantes, houve grande preocupação em preservar o anonimato dos entrevistados. Destarte, informações sobre idade, gênero e outras características gerais não serão aqui divulgadas para dificultar a identificação dos participantes que voluntariamente atenderam ao convite.

Os agentes de aeroporto são responsáveis pelo atendimento ao público no check in, embarque, balcão, marcação de assentos e despacho de bagagem. Também prestam atendimento na loja e fornecem informações gerais.

A tripulação ou equipe de bordo é formada pelo comandante, pelo co-piloto e pelos comissários, porém não é fixa, variando conforme o planejamento da escala de trabalho. Uma vez que a equipe de tripulantes tenha sido convocada, ela se apresenta 45 minutos antes do vôo para conhecer os seus integrantes e trocar informações. Nessa 
oportunidade, são distribuídas responsabilidades a cada membro da equipe. O chefe de cabine permanece em uma mesma posição em todo o período de duração da escala, mas os demais comissários se revezam nas quatro posições restantes. O comandante e o co-piloto têm posições fixas. A jornada é geralmente de cinco dias, e, durante esse período, a tripulação permanece junta, hospedando-se, inclusive, no mesmo hotel.

Os profissionais de RH desenvolvem diversas atividades ligadas à gestão de pessoas, dentre elas, recrutamento, seleção, desenvolvimento de pessoas, avaliação de desempenho, qualidade de vida no trabalho e pesquisa de clima organizacional. São responsáveis também por projetos de responsabilidade social. Ademais, atuam em projetos sociais, como o dos Menores Aprendizes e o projeto Felicidade, que prevê visitas de crianças com câncer na empresa. Eles também fazem atendimento aos empregados da empresa, ministram treinamentos técnicos e desenvolvem projetos de prevenção de acidentes aéreos.

Os dados foram coletados em janeiro de 2007, aproximadamente três meses após o desastre aéreo. As entrevistas foram realizadas em grupo e coordenadas por um dos dois pesquisadores responsáveis. Os agentes de aeroporto e os profissionais de RH trabalhavam juntos em equipes localizadas respectivamente em Brasília e em São Paulo. Os tripulantes entrevistados tinham trabalhado juntos em duas equipes de bordo, imediatamente após o desastre aéreo, e não tinham estado todos juntos até o dia da entrevista em São Paulo. Além deles, estiveram presentes à entrevista alguns auxiliares de pesquisa que registraram em papel os relatos dos participantes.

As entrevistas, com 1 a 2 horas de duração, foram realizadas nos aeroportos de Brasília e São Paulo, em uma sala especialmente designada para esse fim. Após o consentimento livre dos participantes, informação sobre o caráter voluntário da atividade e a garantia de anonimato, duas agentes de aeroporto decidiram não participar, alegando que preferiam não mais lembrar de acontecimentos que eram por demais dolorosos. Esse caráter doloroso foi posteriormente constatado durante as entrevistas, quando vários participantes apresentaram sinais de choro contido ou expresso abertamente. Foi pedida autorização para gravação e dado início à entrevista com base no roteiro apresentado na Tabela 1.

Tabela 1. Roteiro de entrevista.

\begin{tabular}{ll}
\hline Perguntas & Objetivos \\
\hline Descreva sua rotina de trabalho & Conhecer a rotina de trabalho dos participantes \\
& para avaliar o trabalho emocional demandado na \\
& ocupação e na organização
\end{tabular}

Discorra sobre as demandas que surgiram Identificar o impacto das novas demandas provenientes após o acidente fatal de 29 de setembro de clientes, colegas e empresa no trabalho emocional de 2006

Fale sobre as estratégias usadas para lidar com essas novas demandas
Identificar as estratégias de regulação emocional no trabalho segundo um modelo de análise inspirado nas classificações de Grandey (2000), Gross (1998) e Hochschild (1983) 
Após as apresentações iniciais e o esclarecimento dos objetivos da pesquisa, foi solicitado aos participantes que descrevessem a sua rotina de trabalho, para, a seguir, perguntar sobre as demandas que haviam surgido depois do acidente fatal ocorrido em setembro de 2006. Foi pedido também que relatassem e avaliassem a efetividade das estratégias usadas para atender a essas demandas, principalmente aquelas para as quais eles não haviam sido preparados. Em complementação, foi solicitado que eles acrescentassem o que fizeram para evitar ou atenuar o sofrimento daí decorrente.

A hipótese geral da pesquisa era que as novas demandas no contexto de trabalho, após esse trágico evento, aumentaram o trabalho emocional e compeliram os aeroviários da Gol Linhas Aéreas Inteligentes a usarem estratégias de regulação emocional para atenuar o forte impacto emocional negativo e seguir com suas rotinas de trabalho. Tais demandas seriam especialmente novas, não somente pela natureza do evento mas também porque a empresa não tinha passado por qualquer outra experiência dessa natureza, em sua curta existência. Todo o foco da entrevista foi no que ocorreu depois do acidente e em decorrência deste, e não no trabalho emocional que pudesse ser usualmente realizado como parte das atribuições normais da ocupação.

As entrevistas foram analisadas qualitativamente, com base no modelo teórico apresentado na Figura 1. Esse modelo adota como ponto de partida o evento agudo ocorrido no dia 29 de setembro de 2006, em que uma aeronave da empresa colidiu no ar, em grande altitude e sobre a selva amazônica, com outra aeronave de pequeno porte. $\mathrm{O}$ impacto nos empregados da empresa foi relatado como avassalador, como seria esperado. Isso ocorreu, segundo repetidos relatos, não só pela gravidade do fato mas também porque a imagem interna da empresa estava fortemente associada à segurança, a aeronave era nova, o comandante era um dos mais experientes da casa e gozava de excelente conceito profissional entre os colegas.

Pelo fato de o evento ser inesperado, imprevisível e grave, contradizendo a trajetória crescente de sucesso da empresa no mercado nacional, acreditou-se que haveria uma comoção geral, o que levou a direção da organização e os colegas de trabalho a darem suporte uns aos outros para enfrentar as dificuldades dela advindas. Mas, inevitavelmente, novas demandas iriam surgir, o trabalho emocional seria mais requerido e, em conseqüência, os aeroviários teriam de usar mais estratégias de regulação emocional para lidar com essas demandas. O êxito ou fracasso dessas estratégias teria impacto tanto no bem-estar subjetivo de cada empregado (sentimento de satisfação e harmonia pessoal) quanto no bem-estar da organização (bom clima de trabalho, cliente fidelizado e opinião pública favorável à empresa).

O modelo da Figura 1 propõe que o bem-estar subjetivo do trabalho poderia ser inferido a partir da tranqüilidade e do equilíbrio emocional relatado pelos empregados ao lidar com as situações que se sucederam ao evento. Do mesmo modo, os relatos de que estes, com os clientes e o público em geral, estariam satisfeitos com as ações da empresa para enfrentar as conseqüências do episódio seriam indicadores de bem-estar organizacional. 


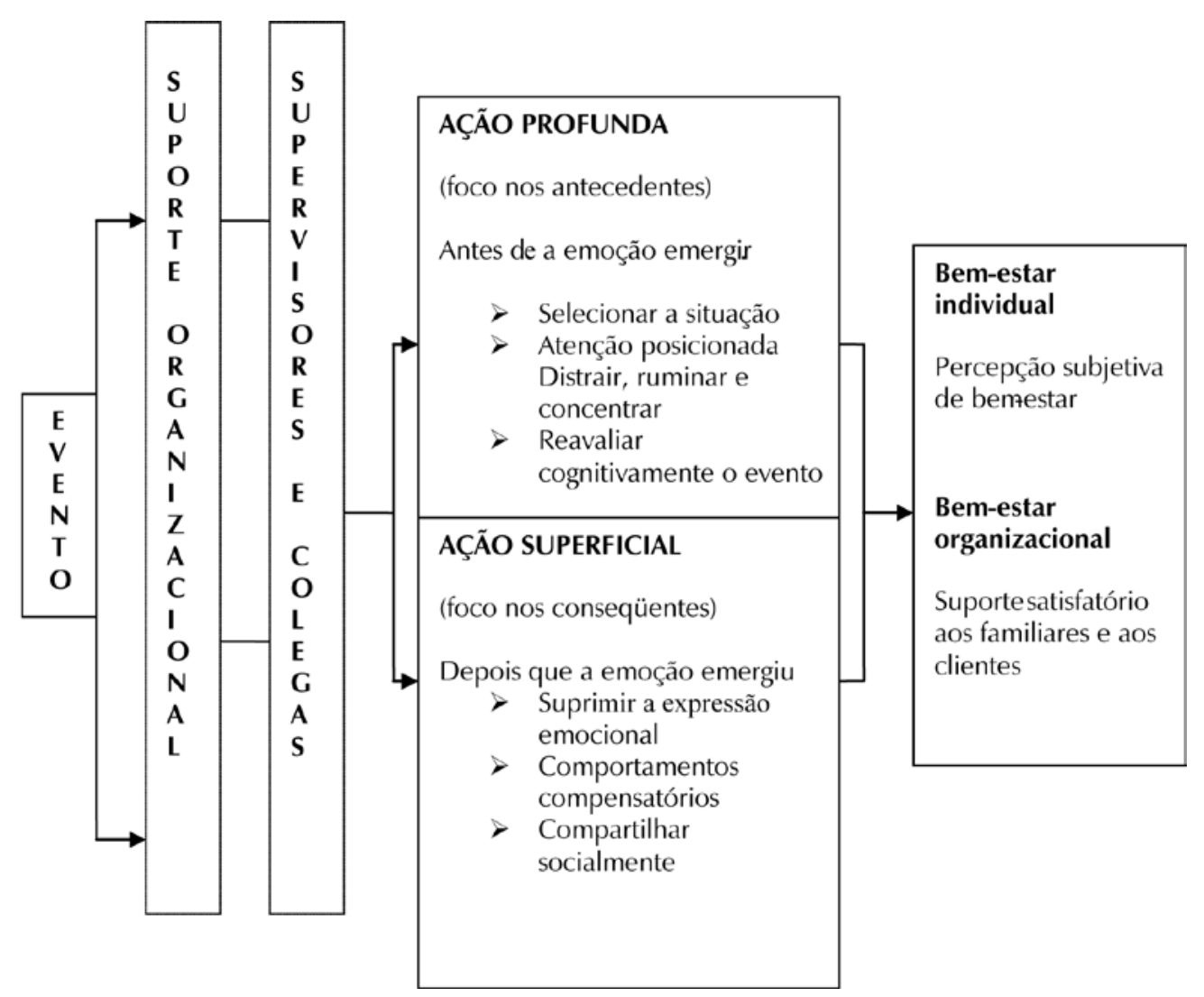

Figura 1. Modelo teórico de análise elaborado a partir dos modelos de Grandey (2000), Gross (1998) e Hochschild (1979, 1983).

\section{Resultados e respectiva discussão}

Esta seção será dividida em duas partes. Na primeira, exploram-se as demandas de trabalho que surgiram após o acidente e seu conseqüente impacto no trabalho emocional. Serão também discutidas as percepções de suporte de colegas e da organização para compreender o momento delicado que estavam vivendo e empreender ações para ajudar na sua superação. Na segunda parte, o foco recairá nas estratégias de regulação da emoção manejadas e relatadas pelos entrevistados, sendo feitos alguns comentários sobre a percepção de bem-estar individual e organizacional. A título de ilustração, serão incluídos alguns excertos de comentários dos entrevistados para exemplificar o seu pensamento.

É importante esclarecer também que a análise dos relatos foi feita em bloco, e não por grupo de entrevistados. Duas razões justificaram essa decisão. A primeira, porque a pesquisa não foi planejada para comparar grupos, mas sim, para apreender a experiência comum de segmentos distintos de empregados após o acidente; a segunda, porque ficou muito claro que as entrevistas se complementavam, não havendo diferenças marcantes entre um ou outro grupo.

"Não é um fardo, mas parece": falando sobre as demandas

No relato dos entrevistados, foram encontrados cinco grupos de demandas de trabalho emocional após o acidente aéreo: dos passageiros, dos parentes das vítimas, dos colegas, pessoais e 
contextuais. Será descrita, a seguir, cada uma dessas demandas separadamente, inclusive exemplos para que o leitor compreenda sua manifestação nas rotinas de trabalho subseqüentes ao acidente.

\section{Demandas dos passageiros}

Três categorias foram identificadas em relação às demandas dos passageiros: aumento do medo de voar, irritação e intolerância e aumento de piadas. Depois do acidente, os passageiros chegavam com mais medo de voar, e isso exigiu dos aeroviários um pouco mais de paciência para ouvir e "jogo de cintura" para convencê-los do contrário, principalmente as crianças. Em contrapartida, os agentes de aeroportos ficaram mais temerosos de comunicar atrasos de avião devido à reação dos passageiros, que tanto faziam piadas como se tornavam agressivos. Mesmo irritados, precisavam dizer: "Não, senhor, sim, senhor". Os tripulantes relataram que o pior era transmitir segurança nos vôos que saíam de Manaus para a Região Centro-Oeste do País, trajeto em que ocorreu o acidente. Por isso, precisaram redobrar a atenção com os passageiros.

O desgaste era tão grande que: "Quando bate o cartão para ir embora, você vê os colegas saírem cansados, parece que carregam um fardo. Não é um fardo, mas parece". Por reconhecer esse momento difícil, a empresa não só contratou serviços psicológicos para dar apoio aos seus colaboradores como proporcionou eventos de dança e encontros (compartilhamento social) para minimizar o estresse decorrente das novas demandas.

A gerente de RH comentou que, após a superação do momento difícil, quando todos os familiares das vítimas já haviam sido atendidos e os corpos enterrados, sua reação foi de cuidar dos empregados: "Agora nós precisamos cuidar de nós mesmos, dos colaboradores". Essas ações favoreceram a percepção dos empregados de que a empresa Ihes dava valor. Em troca, responderam com mais lealdade, como ficou seguidamente evidenciado nos relatos. Nestes, foi dito que brigavam com os amigos quando faziam piadas sobre a empresa, o que é evidência de comprometimento organizacional. Isso parece ter sido ajudado pela forte crença interna de que o acidente havia sido uma fatalidade. "O avião estava na hora errada, no lugar errado, sem se culpar por isso".

A segunda demanda dos passageiros foi o aumento da irritação e da intolerância com as filas, atrasos de vôos e de informação, alguns deles respondendo com ameaças de processos contra a empresa. Esses atrasos duraram algumas semanas e foram depois ampliados, em conseqüência de um movimento nacional organizado por controladores de tráfego aéreo. O impacto maior foi sobre aqueles que trabalhavam na linha de frente (frontstage, na terminologia de Boyle): "Eu levei um murro de um homem. Eu não sou paga para levar murro não, o senhor pode brigar comigo, mas não encosta em mim".

Esse comportamento dos passageiros fez aumentar o medo de os agentes passarem informações erradas em caso de atraso de vôo ou de algum outro problema. A tensão aumentou, segundo os entrevistados, porque a empresa nunca trabalhou com overbooking, como outras empresas faziam, e os vôos eram geralmente pontuais, a não ser em época de alta estação, em que os atrasos chegavam normalmente a 30 minutos. Os agentes não tinham grande experiência para lidar com vôos atrasados, cancelamento de vôos e com o estresse do passageiro. Alguns empregados que não estavam agüentando a pressão dos passageiros ameaçaram se demitir, segundo alguns entrevistados, mas não há informações oficiais se isso efetivamente ocorreu. 
A terceira e última demanda foi a de lidar com o aumento de piadas dos passageiros. Os agentes interpretaram essas piadas como um desrespeito e uma "mexida na ferida". Três piadas sobre o acidente servem de ilustração: "Encontraram dois vivos, não?" "Ah, é?" "Um pós-pago e um pré-pago". "Sabe o que significa Gol? Gente, olha o Legacy!" (Legacy era o nome da outra aeronave que colidiu com a aeronave da empresa). No momento da confirmação do embarque: "Com caixão ou sem caixão?"

\section{Demandas dos parentes das vítimas}

Foram identificados dois tipos de demandas dos parentes das vítimas: número elevado de pessoas a serem atendidas ao mesmo tempo e acompanhamento intenso dos familiares no hotel. O grande número de pessoas que afluíram ao aeroporto à procura de informações dos parentes, e após a notícia oficial de que a aeronave havia caído sem deixar sobreviventes, elevou exponencialmente o volume de trabalho dos aeroviários. Essa demanda, incomum na história da empresa, promoveu a união dos colaboradores: "Veio gente do Brasil inteiro, e começaram a trabalhar sem se conhecerem". "Muitos colegas vieram para o aeroporto para poder ajudar os outros".

Esses comentários são indicativos de que os empregados, ao reconhecerem a gravidade da situação que estavam enfrentando, ofereceram apoio mútuo para suportar a forte carga emocional de trabalho. Gerentes alocados em outros aeroportos em que a empresa operava enviaram empregados para ajudar no atendimento aos familiares das vítimas. Mesmo nunca tendo trabalhado antes nesse tipo de atividade, os entrevistados relataram ter conseguido formar equipes efetivas e desenvolver o trabalho a contento. Na sua percepção, a direção da empresa também se mostrou sensível a isso e contratou bons hotéis para abrigar familiares das vítimas. A equipe de $\mathrm{RH}$ foi deslocada de São Paulo para Brasília, para acompanhar os empregados.

O segundo tipo de demandas dos familiares das vítimas foi a de convivência intensa com eles por mais de 15 dias nos hotéis de Brasília. Isso exigiu mais força e equilíbrio emocional dos empregados. Era preciso regular as emoções pessoais e "não desmoronar diante da família". "Chorar em casa, aqui não!"

Havia o receio também da reação dos familiares das vítimas, que se comportavam de modos distintos e até bizarros: uns reclamavam e eram agressivos, ao passo que outros ficavam quietos, chorando a sua dor. Outra coisa difícil de lidar foram os abusos. Pessoas se fizeram passar por parentes das vítimas para gozar de um final de semana gratuito no hotel contratado pela empresa em Brasília. Houve exigências de roupas de grife, champagne, cerveja, refeições fora do cardápio e calçados novos. Ocorreram indagações sobre opções de lazer em Brasília no final de semana, o que causou grande indignação nos aeroviários. Alguns advogados se fizeram passar por parentes de vítimas para entrar no hotel e distribuir cartões de visita por debaixo das portas dos apartamentos desses parentes, já prevendo a existência de clientes potenciais para ações judiciais.

Alguns traumas foram desencadeados justamente pelos familiares. Uma senhora segurou o braço de uma agente e a sacudiu, gritando: "Você matou meu marido, o que você vai fazer, eu tenho três filhos para criar". Em conseqüência, ela afirmou não tolerar mais que alguém a pegasse pelo braço, pois sempre se lembra da imagem da mulher a agarrando. O que pesou também foi a sensação de impotência. "Não existe ajuda que se possa dar". No relato dos agentes, 
todavia, fica claro que reconhecem que a empresa respeitou os limites emocionais de cada um. Quem não quis ficar no hotel, deu suporte aos outros, levando e trazendo encomendas, mas evitou o contato direto e intensivo com os familiares das vítimas. "Cada um foi até onde podia ir". A equipe de bordo, que fez vários vôos trazendo e levando familiares das vítimas, entre Manaus e Brasília, foi substituída logo que solicitou, pois, depois de três viagens, não suportava mais o peso emocional. Os familiares pediam ao comandante que avisasse quando estivessem sobrevoando o local provável do acidente, o que sempre comovia a todos.

\section{Demandas dos colegas}

Em relação às demandas dos colegas, foram encontradas três categorias de respostas: cooperação na realização da tarefa, aumento do estresse e medo de errar procedimentos. A cooperação foi uma conseqüência da situação extrema em que se encontravam. Alguns empregados eram inexperientes em lidar com emoções fortes, e a alta demanda externa de passageiros do dia a dia e do público em geral exigia controle emocional. Por causa disso, os colegas pediam e davam apoio em momentos de tensão e sobrecarga de trabalho. Houve apoio da equipe que foi treinada para dar assistência à família das vítimas (FAC), mas ela não dava conta da demanda, o que exigia mais comunicação para troca de experiências e orientação do colega menos preparado, até que ele seguisse sozinho quando se sentisse mais confiante. Essa demanda foi considerada positiva, porque aproximou os colegas, dirimindo algumas tensões comuns em ambientes de trabalho. Nesses momentos de intensa convivência, a união aumentou, especialmente no caso das equipes de bordo, que permaneciam cerca de cinco dias longe da família.
Há exemplos de colegas que, ao saberem do acidente, deixaram "o churrasco e a folga" e voltaram ao trabalho em dia de descanso. "A empresa estava precisando. Todo mundo foi solidário. Pessoal de terra, de bordo". "Os colegas estavam preocupados uns com os outros". O estresse entre os colaboradores (backstage, na terminologia de Boyle), no entanto, foi agravado justamente pela obrigatoriedade de manter a paciência com o passageiro, pois, enquanto a calma era mantida para ele, os colegas perdiam a paciência entre si, acirrando atritos internos. O estresse agravou-se também pela não tolerância a erros de procedimentos entre os colegas, principalmente da equipe que estava lidando diretamente com os parentes das vítimas. Em vários momentos, houve polarização, pois alguns estavam preocupados em seguir procedimentos e evitar erros, enquanto outros priorizavam o atendimento às necessidades das famílias, oferecendo respostas mais rápidas, mesmo que estas fugissem aos procedimentos. Esses atritos duravam pouco e cediam lugar à união, segundo os entrevistados.

\section{Demandas pessoais}

Três categorias foram identificadas como demandas pessoais. auto-reflexão sobre a escolha profissional, auto-reflexão sobre o trabalho desenvolvido na organização e atenção aos procedimentos de segurança. A auto-reflexão sobre a escolha profissional esteve presente nos relatos da equipe de bordo: "Será que é isso o que eu quero? É uma profissão de risco". A opinião relativamente compartilhada é que alguns comissários já têm data prevista para mudar de ocupação. A maioria estabelece metas temporárias para permanecer voando: "Eu vou ficar aqui até terminar de pagar o carro". Mas essa crença não emergiu no relato dos comandantes e copilotos ou dos profissionais de $\mathrm{RH}$, sinalizando que a identidade profissional não é construída 
da mesma maneira em todas as categorias ocupacionais de aeroviários.

As auto-reflexões dos profissionais de $\mathrm{RH}$ seguiram outra direção; começaram a se indagar sobre a eficácia dos treinamentos que realizavam, os critérios de seleção usados e a responsabilidade que tinham em relação aos empregados, e isso os fez exigir mais de si mesmos. Em resumo, o acidente levou os funcionários de $\mathrm{RH}$ a repensar o seu papel na empresa, o que "pregavam" e o que efetivamente haviam feito. Não foi uma demanda da empresa, mas uma necessidade pessoal: "Será que precisa acontecer alguma coisa ruim para se fazer alguma coisa pelos colaboradores?" Foi o momento de abrir os olhos: "Que mais podemos fazer para ajudar os colaboradores?" Isso fortaleceu a crença entre os profissionais da área de que as ações de $\mathrm{RH}$ deveriam estar bastante integradas.

A atenção aos procedimentos de segurança foi destacada nos relatos dos comandantes e co-pilotos, pois eles se tornaram bem mais atentos aos instrumentos de segurança disponíveis na aeronave e às orientações dos controladores de vôo. Qualquer ruído estranho aos padrões convencionais passou a requerer atenção e cuidados redobrados.

\section{Demandas contextuais}

O último conjunto de demandas foi classificado como contextual, por terem sido desencadeadas por várias fontes que não as mencionadas anteriormente. São elas: crise dos controladores de tráfego aéreo, perda de confiança no sistema de controle do espaço aéreo brasileiro, aumento de horas extras e pressão da imprensa.

A crise dos controladores de tráfego aéreo agravou bastante a situação e aumentou a demanda por trabalho emocional, pois já não havia mais previsão de saídas e chegadas de vôos. A insatisfação dos passageiros e a tensão emocional no trabalho aumentaram. Os controladores também ficaram mais intolerantes com os pilotos. Eles repetiam mais de uma vez as orientações, e, se estes não as seguissem à risca e se afastassem um pouco da rota, eram chamados à atenção. Por outro lado, os controladores começaram a oferecer mais detalhes dos planos de vôo, o que não acontecia antes do acidente, e esse foi um ponto positivo na avaliação dos comandantes, pois proporcionou mais segurança ao pilotar. Se, de um lado, aumentou a percepção de insegurança no sistema de controle do espaço aéreo brasileiro, por outro lado, pilotos e controladores tornaram-se mais detalhistas e cuidadosos em todos os procedimentos de segurança.

A empresa também passou a requerer ainda mais atenção para os procedimentos de segurança de vôo, exigindo maior rigor na comunicação interna para evitar a transmissão de informações incorretas. As inúmeras demandas que intensificaram o trabalho emocional também fizeram aumentar a quantidade de afastamentos por motivos médicos e, em conseqüência, mais horas extras foram necessárias para suprir o pessoal que estava dispensado. Chegou-se a ter seis ou sete pessoas simultaneamente afastadas do trabalho.

A imprensa também exerceu muita pressão na época. Jornalistas alegavam que a empresa estava escondendo informações, quando, na opinião dos entrevistados, efetivamente não estava. Os repórteres observavam e registravam o que ocorria no aeroporto, em um processo de vigilância constante. Em decorrência disso, os agentes foram muito expostos pela mídia e, portanto, muito assediados mesmo fora do local de trabalho (em transportes coletivos e em paradas de ônibus, por exemplo, se utilizassem o uniforme da empresa). Houve 
Ademais, Asforth

\& Humphrey

(1993) também

sustentam que

o trabalho

emocional

nem sempre é negativo para o trabalhador, atenuando o peso negativo dado a ele na perspectiva de Hochschild (1979, 1983). inclusive uma orientação da empresa para evitar o uso do uniforme fora do local de trabalho, para reduzir esse assédio. Segundo alguns entrevistados, isso foi doloroso, pois compartilhavam orgulho pelo uniforme e antes sentiam prazer em andar com ele fora do local de trabalho.

Resumindo o que foi descrito até agora, foram identificados cinco grupos de demandas que geraram trabalho emocional: as dos passageiros, as pessoais, as dos familiares das vítimas, as dos colegas e as contextuais. Todas elas passaram a requerer dos entrevistados maior habilidade de lidar com as suas próprias emoções e as dos outros com os quais interagiam. Apesar desse flagrante aumento do trabalho emocional, pois a empresa passou a esperar que os trabalhadores da linha de frente (frontstage) exibissem mais emoções integrativas, do tipo simpatia e acolhimento, e suprimissem emoções disruptivas ou mascaradas, houve uma série de atenuantes que fizeram os aeroviários enfrentar essa fase difícil com relativa tranqüilidade, ou seja, preservar o seu bem-estar.

O suporte organizacional e o dos colegas parecem ter sido decisivos, pois contribuíram para que eles compreendessem o problema que enfrentavam, unissem esforços e se ajudassem mutuamente. A organização garantiu apoio psicológico, o pessoal de RH deu apoio no atendimento aos familiares, e os gerentes se envolveram pessoalmente na assistência aos familiares, dando o exemplo aos outros empregados de como agir em situações de grave crise. É possível que o fato de nunca terem passado pela experiência os tenha compelido a darem e a receberem apoio, mais do que o fariam em situações comuns. Os mais experientes orientavam os colegas até que eles se sentissem seguros para seguir adiante sem auxílio. Na literatura científica, há estudos que concluem que o suporte de supervisores e de colegas cria um clima favorável de trabalho que habilita a lidar melhor emocionalmente com as situações de estresse (Cropanzano, Howes, Grandey, \& Toths, 1997). Ademais, Asforth \& Humphrey (1993) também sustentam que o trabalho emocional nem sempre é negativo para o trabalhador, atenuando o peso negativo dado a ele na perspectiva de Hochschild (1979, 1983).

O que chama a atenção também foi o aumento da lealdade à empresa, muito presente nos relatos dos aeroviários. O argumento recorrente foi que a empresa não poderia ser considerada culpada pelo acidente. Com insistência, foi afirmado que não foi imprudência do piloto, tampouco falta de manutenção da aeronave. O avião "foi derrubado" por erros cometidos por terceiros. Embora isso não pudesse desfazer o ocorrido, atenuou o sentimento de impotência e fortaleceu os vínculos organizacionais e a cooperação mútua. Em outras palavras, a forte convicção de que a empresa não havia tido culpa não gerou dissonância entre o sentimento a ser exibido e o efetivamente sentido (Morris \& Feldman, 1996), deixando o caminho livre para a lealdade com a empresa. Afinal, não teria ocorrido traição por parte desta, nas suas relações com os empregados.

Embora a literatura de burnout sinalize que ambientes de trabalho onde há altos níveis de regulação emocional produzam comportamentos de retirada (Malasch \& Pines, 1977), não foi isso que parece ter ocorrido nesse caso. O suporte organizacional e o de colegas parece ter exercido um importante papel moderador.

\section{Estratégias de regulação de emoção}

As estratégias de regulação emocional usadas pelos aeroviários serão descritas de acordo com o modelo de análise ilustrado pela Figura 1. 


\section{Estratégias de ação profunda}

Das três estratégias de ação profundas, cujo foco está localizado nos antecedentes da emoção, em busca de modificar os sentimentos internos para enfrentar a situação, todas foram identificadas nos relatos dos aeroviários: seleção da situação, atenção posicionada e reavaliação cognitiva.

A seleção da situação, caracterizada por evitar situações emocionalmente difíceis, foi usada em quatro contextos: evitar usar o uniforme, evitar interagir com passageiros que faziam piadas do acidente, evitar jornalistas e evitar o trabalho.

Em relação ao uso de uniformes, a orientação dada pela própria empresa foi a de evitar fazê-lo fora do ambiente de trabalho para desestimular a abordagem de transeuntes, imprensa e passageiros, que poderiam perturbar o estado emocional dos aeroviários. A demanda de trabalho emocional aumentava quando estavam uniformizados, pois, nesse caso, eles precisavam zelar pela imagem da empresa, sendo polidos no tratamento interpessoal, mesmo estando fora dela.

Nem sempre a interação com os passageiros era boa, principalmente com aqueles que faziam piadas: "Houve situação em que o passageiro fez uma piada e o atendente não agüentou e saiu chorando". Como já foi discutido antes, os aeroviários interpretavam essas piadas como uma "mexida na ferida" que ainda não estava cicatrizada, e também como um desrespeito ao seu sofrimento, pois teriam perdido colegas de trabalho no acidente. Destarte, quando identificavam um passageiro que dava indícios de se comportar desse modo, evitavam prolongar a interação, restringindo-a ao estritamente necessário.

Os jornalistas também passaram a ser personas non gratas, pelo estresse da alta exposição a que sujeitaram os aeroviários durante o período que sucedeu o acidente fatal. Como mencionado antes, quando foram discutidas as demandas de trabalho emocional após o acidente, os jornalistas registravam imagens e acompanhavam tudo o que ocorria, sendo responsáveis inclusive por episódios desagradáveis nos hotéis que hospedaram os familiares. Alguns muniram de informações pessoas inescrupulosas, que as usavam para ter acesso aos hotéis, fazendo-se passar por parentes de vítimas para obtenção e divulgação de informações sobre o sofrimento dos parentes das vítimas.

A outra situação evitada foi o próprio trabalho. Isso esteve presente no relato de profissionais de RH. Depois de três semanas, uma gerente desse setor não conseguiu ir ao trabalho, pois estava febril e afônica. O sentimento era de que precisava de um dia para descansar e cuidar de si mesma. Segundo ela, não era uma doença propriamente dita, mas uma forma de evitar ir ao trabalho. No dia seguinte, os sintomas haviam desaparecido. Ela precisava de um tempo para se recuperar.

A atenção posicionada é caracterizada como os esforços que os aeroviários fizeram para manter o bom humor, fixando a mente em pensamentos e sentimentos positivos. Essa seria uma forma de driblar o estado emocional interno e manter longe do pensamento as memórias do acidente que poderiam impedir o trabalho (uma estratégia mista que une distração e concentração).

Tal comportamento constituiu um desafio, porque alguns passageiros chegavam de mau humor e eles tinham de "estar bem" para lidar com eles: "Bom dia, senhor, qual é o destino?" E o passageiro respondeu: "Não sabe ler, não? Está no papel". "Bom dia, senhor, qual é o destino?" E recebeu como resposta: "O inferno". E eles desabafavam: "Você faz uma força danada, porque os outros passageiros não têm nada a ver com isso". 
A maior fonte de força dos aeroviários eram as lembranças dos elogios dos passageiros. Concentravam sua atenção principalmente nos gestos de agradecimento que receberam de familiares. Houve um caso comovente do parente de uma vítima que merece ser comentado: "Eu entrei, odiava vocês porque tinham tirado a pessoa que eu mais amava, depois achei que faziam isso porque eram obrigados; agora sei que vocês estavam sofrendo junto com a gente". Essa estratégia de manter o foco de atenção nos elogios, mais do que nas críticas, parece ter funcionado relativamente bem para os aeroviários: "Eu fui chorar quatro dias depois. $O$ fato de eu ter feito muito treinamento me ajudou muito, pois eu coloquei em prática o que havia aprendido no treinamento". "Antes de chorar e me emocionar, devo pensar nas coisas positivas que aprendi no curso". Parece que esses comentários sinalizam que os aeroviários aprenderam a lidar com os sentimentos durante esses momentos difíceis.

A força também foi buscada na visualização de uma meta de realização: "Olhar para a frente. Tenho que continuar cumprindo o meu papel". Na prática, é mirar um objetivo e pensar que a empresa precisa continuar funcionando. Dá força para manter o estado de humor positivo e esquecer o sofrimento. Novamente encontram-se indícios de lealdade à empresa: "A empresa precisa de mim". "Eu não posso me apegar a isso, senão eu vou viver o luto, e eu não posso viver o luto agora".

A preocupação em manter o estado de humor fez com que também fossem evitadas algumas situações que poderiam desencadear emoções fortes. Os instrutores, por exemplo, na semana do acidente, deixaram de colocar jingle da empresa e imagens que emocionassem, para evitar que as pessoas mais sensíveis chorassem. Nesse caso, a estratégia de atenção posicionada foi associada à estratégia de seleção de situação para tornar mais efetiva a regulação da emoção.

De um lado, o uso dessa estratégia de atenção posicionada esteve atrelado à lealdade da empresa e ao reconhecimento de que ela estava precisando dos empregados. Era uma "questão de profissionalismo", que, sem dúvida, demandava trabalho emocional. Em contrapartida, empregados das equipes de bordo relataram ter usado essa estratégia porque passaram a valorizar mais a vida e o fato de estar próximo de seus familiares. Estavam em atividade de risco, e seria importante se sentirem bem para cuidar dos familiares.

É preciso ressaltar, todavia, que o esforço de manter o bem-estar pessoal se concentrando em sentimentos e eventos positivos nem sempre funcionou fora do ambiente de trabalho (diríamos que é um offstage invertido, seguindo a terminologia de Boyle). Entrevistados relataram que levavam para casa as tensões emocionais vividas no trabalho, e os eventos ruins emergiam durante os sonhos: "Sonhar com a cara do pessoal caindo". "O mau cheiro dos corpos chegando no aeroporto. É difícil esquecer!" Ao chegar em casa, o noticiário trazia informações. Pessoas e amigos ligavam e perguntavam, trazendo à tona aquilo que queriam esquecer.

Aparentemente, os resultados da empresa, que sinalizariam bem-estar organizacional, foram dúbios. Alguns aeroviários ficaram mais dispersos nos dois primeiros meses pelo impacto emocional, mas outros ficaram mais atentos aos procedimentos para evitar erros (de atendimento, reclamações, atrasos, avarias e perdas de bagagem, etc). A crise dos controladores de vôo dos aeroportos piorou a situação, principalmente porque: "O erro acontece muito pelo atraso de aviões, bagagem enviada para outro destino e perda de conexões". 
Mesmo no trabalho, nem sempre a estratégia de atenção posicionada conseguiu ser bem sucedida: "A gente tentava não lembrar, mas toda hora chegava algum documento de alguma vítima. E enquanto todos os mortos não foram enterrados, não acalmou. E a imprensa ajudou a deixar a gente muito tantã".

A última estratégia de ação profunda mencionada pelos aeroviários foi a reavaliação cognitiva. As principais formas de avaliação foram: pensar que a grosseria dos passageiros não é com eles, pensar que outras empresas já passaram por isso e conseguiram vencer e colocar-se no lugar do outro. Pensar que a grosseria vinda dos passageiros era por causa da situação que estavam vivendo, sem ter relação com eles, permitiu que fossem mais compreensíveis com os passageiros e os escutassem com mais atenção, mesmo que muitas vezes estivessem reclamando sem razão; pensar que as outras empresas já haviam passado por eventos semelhantes e sobreviveram deu-lhes força para pensar que conseguiriam superar os momentos mais difíceis.

Colocar-se no lugar do parente da vítima e dos passageiros e entender o que eles estavam sentindo ajudou os aeroviários a desenvolverem a empatia, e puderam então ser mais pacientes. Eles reconheceram que a viagem de avião é um evento que "mexe" com a vida das pessoas, que se locomovem para cumprir compromissos importantes, quer de negócios, quer de férias. Compreenderam também que transtornos no aeroporto "mexiam" com as emoções da pessoa: "O estresse da situação que o cliente está vivendo vem todo para você". "Você é o final da linha de todo estresse que ele teve. Se você não estiver preparado, você acaba brigando com ele". "As pessoas precisam descarregar em alguém". "A gente adquiriu muita maturidade".
Colocar-se no lugar do outro que estava sofrendo parece ter ajudado bastante: "Se fosse comigo, eu queria que fizesse o mínimo, tudo que nós estamos fazendo e algo mais". O exemplo da mãe de uma comissária que morreu no acidente fatal reforçou essa estratégia empática. Ela declarou na televisão que não estava tão sentida, porque a filha tinha morrido fazendo o que gostava. "Depois disso, eu fiquei mais tranqüila, porque a minha falaria a mesma coisa, se fosse eu". "O meu sofrimento perto do filho do comandante que morreu ou de cada família da vítima não é nada. A gente passa por cima do nosso sofrimento".

\section{Estratégias de ação superficial}

Das estratégias de ação superficial, cujo foco é no conseqüente, ou seja, quando a emoção já foi desencadeada, foram identificadas as seguintes: supressão e intensificação da expressão emocional, comportamentos compensatórios para controle de aspectos fisiológicos e compartilhamento social.

Sorrir, ainda que se esteja com raiva do passageiro que está sendo grosseiro, insistindo para liberar excesso de bagagem ou sendo descortês por causa de atrasos e filas, ilustra a estratégia superficial de suprimir a expressão negativa para exibir aquela que seria apropriada à situação.

Além de suprimir a expressão considerada negativa, os aeroviários encontraram uma alternativa menos dolorosa para enfrentar a demanda de trabalho emocional, que foi a de manter firmeza no enfrentamento com o cliente, para que este recuasse em sua tentativa de intimidar ou fazer piada. Um exemplo ilustrativo do uso dessa estratégia foi dado por uma agente de aeroporto. O passageiro the disse: "O avião vai cair?" A agente respondeu com voz firme e expressão séria ao supor que a pergunta fazia alusão à 
queda do avião sucedida em setembro de 2006: "O avião não caiu, ele foi derrubado. Mais alguma informação, senhor? Boa viagem. O próximo". Segundo ela, a pessoa que vinha depois na fila, ainda que estivesse pensando em fazer alguma brincadeira, se sentia desestimulada a partir daquela reação. E ela passou a ensinar a estratégia aos colegas: "O passageiro alterou a voz, afasta, levanta e mostra uma expressão facial firme. Ele fica intimidado, e funciona. Ele desarma".

Ao contrário do que se poderia supor, o uso de comportamentos compensatórios para lidar com aspectos fisiológicos não esteve tão presente nos relatos dos aeroviários, embora tenha sido mencionado o alongamento do corpo depois da jornada de trabalho para aliviar a irritação e o adoecimento. Apesar do pouco uso dessa estratégia servir de indício de como os empregados conseguiram lidar bem com uma situação emocional difícil antes de ela efetivamente ocorrer (estratégias profundas), reconhece-se que, ao serem indagados dos problemas de saúde de colegas após o acidente, crises de cefaléia, depressão, disfunção hormonal e obesidade tenham sido relatados. $\mathrm{O}$ impacto maior parece ter sido nos menos experientes. Isso sugere uma relação a ser explorada entre experiência de trabalho e habilidade de manejar estados afetivos, que, bem arranjada, poderia atenuar a carga de trabalho emocional.

Não ficou muito evidenciado na fala dos entrevistados o uso do compartilhamento social das emoções, também classificado como uma estratégia superficial. É preciso considerar, todavia, que o evento trágico afetou toda a empresa e, desde o início, requereu união e cooperação no trabalho. Era a empresa inteira lutando para manter a sua credibilidade perante a opinião pública. A manutenção dos empregos também dependia do sucesso em realizar essa tarefa, pois estes dependiam da sustentabilidade organizacional, como foi ressaltado por muitos entrevistados. Era um esforço coletivo, e não uma estratégia individual do empregado. $\mathrm{O}$ compartilhamento, então, parece ter sido uma conseqüência direta dessa aproximação. Os colegas faziam chamadas telefônicas entre si para perguntar como o outro estava se sentindo e trocar informações. O que parece ter contribuído fortemente para esse compartilhamento foi o sentimento comum de que o acidente foi uma fatalidade, e não um erro da empresa; não tinham por que se sentir culpados, e nem assumir a defesa de uma empresa que agiu de modo irresponsável. Se fosse esse o caso, o trabalho emocional requerido teria conseqüências muito mais desastrosas: "A culpa não foi nossa. Os próprios passageiros entenderam isso. Os brasileiros reconheceram que não foi culpa da empresa". "A gente sabe, a empresa valorizava a segurança. Tinham aviões novos. Todos tinham uma garantia muito grande. A manutenção, e todos, zelavam pela segurança, e o acidente ocorreu".

O acidente fez vir à tona o sentimento de fragilidade e impotência que os empregados não imaginavam possuir: "Eles não tiveram oportunidade de fazer nada. Não foi falta de manutenção, não foi falha técnica". O sentimento que ficou é o de injustiça. De qualquer modo, o erro, mesmo que cometido por terceiros, aparentemente contribuiu para o aprendizado, principalmente para os mais novos, que cresceram com a empresa, sem nunca terem presenciado ou imaginado testemunhar as conseqüências de um acidente dessa magnitude. Os pilotos mais experientes, e que vieram de outras companhias, no entanto, lidaram de modo diferente com o evento, pois perceberam o acidente como um risco do trabalho na aviação. Isso fortalece o argumento anterior de que a experiência de trabalho parece exercer um papel importante na atenuação do trabalho emocional, capacitando a pessoa a regular suas emoções de modo menos doloroso. 
Os eventos que se sucederam ao desastre fizeram refletir que não bastava oferecer cursos sobre como lidar com situações dessa natureza, pois isso não seria uma garantia de domínio de competência: "Só quando você passa pela situação" é que pode dimensionar o quanto está preparado. Todos devem ser treinados, e não apenas um grupo de especialistas, pois a experiência mostrou que alguns dos treinados não se sentiram preparados para enfrentar a situação quando ela efetivamente ocorreu. A experiência também proporcionou aprendizado, porque forneceu insumos concretos (fotos, documentação) do que poderá vir a ocorrer, o que foi usado para modificar os planos de emergência hoje em vigor na empresa.

\section{Considerações finais}

Uma das conclusões mais importantes que se pode extrair deste estudo de caso é que o ser humano tem grande capacidade de manter o equilíbrio emocional e superar o trauma, se contar com o apoio social. Existe bastante diversidade individual para manejar emoções, mas o suporte mútuo é capaz de reduzir as diferenças e fortalecer o sentimento de grupo. Se um evento trágico é capaz de gerar muitas e diversificadas demandas de trabalho emocional, nem sempre ele é um fardo pesado demais para as pessoas. Asforth e Humphrey (1993) chamavam a atenção para isso, contrapondo-se à perspectiva de Hochschild (1983), para quem o trabalho emocional é prejudicial ao bem-estar do trabalhador. No caso específico deste estudo, a forte crença compartilhada de que o desastre não foi negligência da empresa ou irresponsabilidade da equipe de bordo ou ainda de ausência de manutenção pode ter sido um fator chave.

É também possível concluir que o trabalho emocional se torna um fardo quando existe dissonância entre o que se sente e o que se deve sentir e expressar. Isso está em concordância com o que Morris e Feldman (1996) afirmam sobre a percepção da dissonância ser uma variável importante para levar os trabalhadores a fazerem uso de estratégias profundas, mais do que estratégias superficiais, estas últimas consideradas por Hochschild (1983) como as mais prejudiciais.

Os trabalhadores estudados, com aquela crença fortemente compartilhada e a percepção de suporte, responderam com lealdade, tolerando o trabalho emocional. Talvez essa seja uma das razões pelas quais eles tenham privilegiado o uso de estratégias de ação profunda, em vez de estratégias superficiais. Rafaeli e Sutton (1987) sustentam que o uso de estratégias de ação profunda é um sinal de que o indivíduo tem um vínculo positivo com a organização a ponto de se sacrificar por ela. Trazendo para o presente caso, ao estarem dispostos a colaborar com a organização, os aeroviários investiam na mudança de seus sentimentos internos para se sentirem mais fortalecidos e lidar melhor com as demandas de passageiros, parentes das vítimas, colegas, imprensa, empresa e sociedade. Tal fato não significa que não tenham feito uso de estratégias de ação superficial, tais como a supressão e a intensificação das expressões, embora as estratégias de ação profunda aparentemente tenham ocupado um papel central no processo de regulação de suas emoções.

Por prudência, é preciso reconhecer que, embora este estudo indique que as estratégias de ação profunda tenham sido mais centrais do que as estratégias superficiais, os estudos empíricos não são conclusivos sobre a efetividade das estratégias de regulação emocional. Estudos com casais concluem que, embora o controle das expressões faciais (suprimir ou intensificar) tenha um papel destacado nos relacionamentos maritais, não ajuda muito a reduzir os sentimentos 
pessoais negativos, e ainda prejudica a saúde (Carstensen, Gottman, \& Levenson, 1995), mas a reavaliação cognitiva, ao contrário, apesar de ser mais difícil de ser realizada, é considerada mais efetiva para reduzir esses sentimentos (Gross, 1998).

Os resultados também permitem concluir que, ao contrário do que Grandey (2000) afirma, os trabalhadores do setor de serviços fazem uso de estratégias de seleção da situação. A premissa dessa autora é que os trabalhadores que atuam no setor não têm a opção de evitar clientes indelicados e descorteses, pois o atendimento é a sua principal atividade. Todavia, a análise dos relatos dos aeroviários contradiz essa afirmativa, o que pode ser explicado pelo fato de a própria empresa ter interesse de preservar sua imagem social em momentos de crise e, em sendo assim, ter orientado os empregados a evitarem situações que pudessem prejudicar ainda mais essa imagem.

Os estudiosos alertam que, apesar de as estratégias de regulação emocional serem usadas para minimizar o impacto emocional negativo ou intensificar o positivo, todas elas têm um custo pessoal. Na prática, evitar desprazer e buscar prazer podem ter alto custo humano, mas esse custo pode ser atenuado pelo suporte social, ou seja, pelos recursos providos por outras pessoas (Stansfeld, 2006), principalmente oriundos das organizações (Mearns, Hope \& Reader, 2006).

Emergiram evidências, dos relatos dos entrevistados, de que a empresa cresceu muito rapidamente e não estava ainda preparada para enfrentar o que ocorreu. A forte imagem de segurança da empresa não levava a supor que uma fatalidade, do porte da que ocorreu, viesse a ocorrer um dia. Diante dela, a percepção freqüente foi que a empresa agiu corretamente ao manter um fluxo de informações e dar total assistência às famílias e liberdade para que eles fizessem o trabalho, respeitando os seus limites pessoais: "Eu já trabalhei em empresas que não agiram assim".

O estudo de caso aqui descrito permitiu extrair importantes indicadores que, no futuro, poderão compor um instrumento de medida de trabalho emocional, a ser padronizado e validado no contexto nacional. A literatura internacional de trabalho emocional já dispõe de instrumentos de mensuração validados (por exemplo, Glomb \& Tews, 2004), mas ainda há muita discussão sobre a imprecisão conceitual. Em parte, essa discussão é herdeira da falta de consenso nos estudos de inteligência emocional, dada a forte vinculação entre esse último conceito e o de trabalho emocional. Um sinal disso é o número expressivo de instrumentos de mensuração de inteligência emocional disponíveis na literatura (Pérez-González, Petrides, \& Furnham, 2007; Siqueira, Barbosa, \& Alves, 1999). Os estudos, no entanto, não são conclusivos quanto ao fato de a inteligência emocional estar correlacionada à personalidade (Law, Wong, \& Song, 2004) e de ser um preditor do desempenho no trabalho (Van Rooy \& Viswesvaran, 2004). Portanto, a construção de um instrumento de diagnóstico do trabalho emocional sem dúvida traria contribuições relevantes para esse debate, particularmente porque ainda é um campo aberto a ser explorado no Brasil.

Por ser este um estudo qualitativo de um único caso, não é possível assegurar que o sucedido nessa empresa se repetiria em outras, e nem que, ao vir a acontecer outro acidente na mesma empresa, os aeroviários agiriam do mesmo modo. A análise deste caso também deixa claro que as emoções e a maneira como se lida com elas não são um fenômeno individual explicado apenas pelas diferenças pessoais. Como os construcionistas 
sociais e culturalistas sustentam (por exemplo, Averill, 1980; Harré, 1986; Mesquita, 2003; Parkinson et al., 2005; Turner \& Stets, 2005), a maneira de manifestar e gerenciar as emoções é um processo coletivamente construído na interação cotidiana com os demais.

A percepção de suporte social, quer de colegas, quer da organização, fortalece os elos afetivos e diminui o impacto emocional de ter de manejar situações de interação difíceis. Talvez a cultura brasileira coletivista explique a centralidade das estratégias de ação profunda e o aumento da lealdade à empresa. Sem dúvida, outros estudos lançariam mais luz sobre essa questão. Há algo, todavia, que parece estar além da cultura (talvez um traço evolutivo) e é um potencial aliado para lidar com as emoções que inquietam e nos molestam tanto: o tempo. "O tempo faz a gente lidar melhor com a situação. Somos todos mais experientes hoje".

\section{Sonia Maria Guedes Gondim*}

Doutora em Psicologia Social e da Personalidade pela UFRJ; professora associada do Instituto de Psicologia/ NPGA/CIAGS - UFBA.

\section{Jairo Eduardo Borges-Andrade}

Ph.D em Sistemas Instrucionais, Florida State University; professor do Departamento de Psicologia Social e do Trabalho - Instituto de Psicologia da Universidade de Brasília.

E-mail: jairo@unb.br

\section{*Endereço para envio de correspondência:}

Rua Rodrigo Argolo, 293 apto 502 - Rio Vermelho - Salvador - BA - Brasil, CEP: 41940-220

E-mail: sggondim@ufba.br 
Referências
Arnold, M. B., \& Gasson, J. A. (1954). Feelings and emotions as dynamic factors in personality integration. In M. B. Arnold \& S. J. Gasson (Eds.), The human person (pp. 294-313). New York: Ronald.

Ashforth, B. E., \& Humphrey, R. H. (1993). Emotional labor in service roles: The influence of identity. Academy of Management Review, 18, 88-115.

Averill, J. R. (1980). A constructivist view of emotion. In R. Plutchik \& H. Kellerman (Eds.), Emotion: Theory, research and experience (pp. 305-339). New York: Academic Press.

Boyle, M. V. (2005). "You wait until you get home". Emotional regions, emotional process work, and the role of onstage or offstage support. In C. E. J. Härtel, W. J. Zerbe, \& N. M. Ashkanasy (Eds.), Emotions in organizational behavior (pp. 45-65). London: Lawrence Erlbaum.

Carstensen, L. L., Gottman, J. M., \& Levenson, R. W. (1995). Emotional behaviour in long term marriage. Psychology and Aging, 10, 140-149.

Cropanzano, R., Howes, J., Grandey, A., \& Toths, P. (1997). The relationship of organizational politics and support to work behaviours, attitudes, and stress. Journal of Organizational Behavior, 18, 159-180.

Damasio, A. R. (1994). Descartes's error. New York: Putnam.

Elster, J. (2007). Explaining social behavior. More nuts and bolts for the social sciences. New York: Cambridge University Press.

Ekman, P., Friesen, W. V., \& Ellsworth, P. (1972). Emotion in the human face: Guidelines for research and an integration of findings. New York: Pergamon.

Fridja, N. H. (1986). The emotions. New York: Cambridge University Press

Glomb, T. M., \& Tews, M. J. (2004). Emotional labor: A conceptualization and scale development. Journal of Vocational Behavior, 64, 1-23.

Goffman, E. (1959). Presentation of self in everyday life. New York: Overbook Press.

Gondim, S. M. G., \& Alvaro, J. L. (n.d.). Naturaleza y cultura en el estudio de las emociones. (Trabalho não publicado)

Grandey, A. A. (2000). Emotion regulation in the workplace: A new way to conceptualize emotional labor. Journal of Occupational Health Psychology, 5, 95-110

Gross, J. (1998). The emergent field of emotion regulation: An integrative review. Review of General Psychology, 2, 271-299.

Gross, J. (1999). Emotion regulation. Past, present, future. Cognition and Emotion, 13, 551-573.

Grove, S. J., \& Fisk, R. P. (1989). Impression management in services marketing: A dramaturgical perspective. In R. A. Giacalone \& P. Rosenfeld (Eds.), Impression management in the organization (pp. 427-438). Hillsdale, NJ: Erlbaum.

Harré, R. (Ed.). (1986). The social construction of emotions. Oxford, England: Basil Blackwell.

Hochschild, A. R. (1979). Emotion work, feeling rules, and social structure. American Journal of Sociology, 85, 551-575.

Hochschild, A. R. (1983). The managed heart. Commercialization of human feeling. Los Angeles: University of California Press.

Izard, C. E. (1977). Human emotions. New York: Plenum.

James, W. (1884). What is an emotion? Mind, 9, 188-205.

Lazarus, R. S. (1966). Psychological stress and coping process. New York: McGrawHill.

Law, K. S., Wong, C., \& Song, L. J. (2004). The construct and criterion validity of emotional intelligence and its potential utility for management studies. Journal of Applied Psychology, 89(3), 483-496.
Lewis, M \& Michalson, L. (1983). Children's emotions and moods: Developmental theory and mesurement. New York: Plenum.

Lutz, C. (1988). Unnatural emotions: Everyday sentiments on a micronesian atoll and their challenge to western theory. Chicago: University of Chicago Press.

Malasch, C., \& Pines, A. (1977). The burn-out syndrome in the day care setting. Child Care Quarterly, 6, 100-113.

Mearns, K., Hope, L., \& Reader, T. (2006). Health and well-being in the offshore environment. The role of the organisational support. Norwich, UK: Health and Safety Executive.

Mesquita, B. (2003). Emotions as dynamic cultural phenomena. In R. J. Davidson, K. R. Scherer, \& H. H. Goldsmith (Eds.), Handbook of affective sciences (pp. 871-890). Oxford, UK: Oxford University Press.

Miller, K., Considine, J., \& Garner, J. (2007). "Let me tell you about my job": Exploring the terrain of emotion in the workplace. Management Communication Quarterly, 20, 231- 260.

Morris, J. A., \& Feldman, D. C. (1996). The dimensions, antecedents, and consequences of emotional labor. Academy of Management Review, 21, 986-1010.

Niedenthal, P. M., Krauth-Gruber, S., \& Ric, F. (2006). Psychology of emotion. Interpersonal, experiential, and cognitive approaches. New York: The Psychology Press.

Parkinson, B., Fischer, A. H., \& Manstead, A. S. R. (2005). Emotion in social relations. Cultural, group, and interpersonal processes. New York: Psychology Press.

Pérez-González, J. C., Petrides, K. V., \& Furnham, A. (2007). La medida de la inteligencia emocional rasgo. In J. M. M. Navas \& P. F. Berrocal (Orgs.), Manual de inteligencia emocional (pp. 81-97). Madrid: Pirâmide.

Rafaeli, A., \& Sutton, R I. (1987). The expression of emotion in organizational life. In I. I. Cunnings \& B. M. Staw (Eds.), Research in organizational behavior (Vol. 11, pp. 1-42). Greenwich, CT: JAI Press.

Rimé, B., Mesquita, B., Philippot, P., \& Boca, D. (1991). Beyond the emotional event: Six studies on the social sharing of emotion. Cognition and Emotion, 5, 435-465.

Rimé, B., Finkenauer, C., Luminet, O., Zech, E., \& Philippot, P. (1998). Social sharing of emotion: New evidence and new questions. In W. Stroebe \& M. Hewstone (Eds.), European review of social psychology (Vol. 9, pp. 145-189). Chichester: John Wiley \& Sons.

Röttger-Rössler, B., \& Markowitsch, H. J. (Eds). (2009). Emotions as bio-cultural processes. New York: Springer.

Saarni, C. (2004). The social context of emotional development. In M. Lewis \& J. M. Haviland-Jones (Eds.), Handbook of emotions (2nd ed., pp. 306-322). New York: The Guilford Press.

Scherer, R. (1999). Appraisal theories. In T. Dalgleish \& M. Power (Eds.), Handbook of cognition and emotion (pp. 637-663). Chichester, NJ: John Wiley \& Sons.

Siqueira, M. M. M., Barbosa, N. C., \& Alves, M. T. (1999). Construção e validação fatorial de uma medida de inteligência emocional. Psicologia: Teoria e Pesquisa, 15(2), 143-152.

Stansfeld, S. A. (2006). Social support and social cohesion. In S. Marmot \& R. G. Wikinson (Eds.), Social determinants of health (pp. 149-169). Oxford, UK: Oxford University Press.

Tomkins, S. S. (1962). Affect, imagery, consciousness. Vol 1: The positive affects. New York: Springer.

Turner, J. H., \& Stets, J. E. (2005). The sociology of emotions. Cambridge, UK: The Cambridge.

Van Rooy, D. L., \& Viswesvaran, C. (2004). Emotional intelligence: A meta-analytic investigation of predictive validity and nomological net. Journal of Vocational Behavior, 65, 71-95. 